\title{
ON THE DURABILITY OF RESIN-DENTIN BONDS: IDENTIFYING THE WEAKEST LINKS
}

\begin{abstract}
Fatigue of resin-dentin adhesive bonds is critical to the longevity of resin composite restorations. Objectives: The objectives were to characterize the fatigue and fatigue crack growth resistance of resin-dentin bonds achieved using two different commercial adhesives and to identify apparent "weak-links". Methods: Bonded interface specimens were prepared using Adper Single Bond Plus (SB) or Adper Scotchbond Multi-Purpose (SBMP) adhesives and 3M Z100 resin composite according to the manufacturers instructions. The stress-life fatigue behavior was evaluated using the twin bonded interface approach and the fatigue crack growth resistance was examined using bonded interface Compact Tension (CT) specimens. Fatigue properties of the interfaces were compared to those of the resin-adhesive, resin composite and coronal dentin. Results: The fatigue strength of the SBMP interface was significantly greater than that achieved by SB $(\mathrm{p} \leq 0.01)$. Both bonded interfaces exhibited significantly lower fatigue strength than that of the Z100 and dentin. Regarding the fatigue crack growth resistance, the stress intensity threshold $\left(\Delta \mathrm{K}_{\mathrm{th}}\right)$ of the SB interface was significantly greater $(\mathrm{p} \leq 0.01)$ than that of the SBMP, whereas the $\Delta \mathrm{K}_{\mathrm{th}}$ of the interfaces was more than twice that of the parent adhesives. Significance: Collagen fibril reinforcement of the resin adhesive is essential to the fatigue crack growth resistance of resin-dentin bonds. Resin tags that are not well hybridized into the surrounding intertubular dentin and/or poor collagen integrity are detrimental to the bonded interface durability.
\end{abstract}

Key Words: crack, dentin bonding, durability, fatigue, fracture, 


\section{INTRODUCTION}

Fatigue of materials is gaining recognition in the field of restorative dentistry. Indeed, fatigue is now recognized as either the primary mode of failure or a contributing mechanism for both direct and indirect restoratives [e.g. 1,2]. As such, the fatigue properties of dental materials and the durability of their bonds to tooth structure are important metrics of performance.

Fatigue failure of dental composites has received attention for over two decades [e.g. 311]. Recent in vitro evaluations and clinical outcomes suggest that the fatigue properties of resin composites may be useful in predicting clinical performance [12, 13]. Lohbauer et al. [1] emphasized the importance of considering the fatigue strength of resin composites during materials selection, and commented that experimental investigations on fatigue performance should involve clinically relevant geometries and loading conditions.

While chemical degradation of the bonded interface is a longstanding concern, cyclic stresses are considered a contributing factor to its progressive degradation over time [14, 15]. In fact, the bonded interface has been regarded as the weakest link of resin-dentin bonds [14]. Studies on fatigue of tooth-resin bonds began almost as early as those on resin composites [16, 17]. Yet, relatively few investigations have been reported in this area [18-24]. There has been an attempt at modeling the fatigue behavior of the resin-dentin adhesive interface using the finite element method [25]. Results from prior studies have distinguished that bonded interfaces are not resilient to cyclic loads, with fatigue strengths reported to be as low as $25 \%$ of the static strength.

Belli et al. [24] recommended that a combination of experimental approaches should be used to obtain a broader picture of the bonded interface performance. In a comparison of two different adhesive systems, they applied both static and cyclic methods of loading. While there was no difference in strength of the two adhesive systems under static loads, there was a 
significant difference in their fatigue strength. The difference in fatigue behavior was attributed to an unequal population of flaws within the adhesive layers. If flaws are located at the interface, within either the resin adhesive or the hybrid layer, then the "initiation" phase of the fatigue life is relatively short. In these instances, the bonded interface durability will be related to its resistance to the "propagation" of these defects via cyclic extension. Soappman et al. [26] proposed evaluating the fatigue crack growth resistance of resin-dentin bonds using a conventional fracture mechanics approach. However, that investigation did not perform a complimentary evaluation of the interface via static loading or stress-life fatigue. All of these modes of loading are relevant to the durability of tooth-resin composite bonded interfaces.

The present study adopts three approaches for evaluating the durability of resin-dentin adhesive bonds. Specifically, the flexure strength, stress-life fatigue and fatigue crack growth properties of dentin-resin bonded interfaces were characterized, and the results were compared with those obtained for the individual materials (i.e. dentin, resin adhesive and resin composite). The overall objective of this investigation was to evaluate the fatigue resistance of dentin bonds developed using two selected commercial materials and to assess the "weakest-link".

\section{MATERIALS AND METHODS}

The durability of resin-dentin bonds resulting from two different commercial adhesive systems was evaluated in terms of the stress-life fatigue and fatigue crack growth responses. Both approaches involved sections of human coronal dentin, which was obtained from cariesfree third molars. The teeth were obtained from participating clinics in Maryland according to an

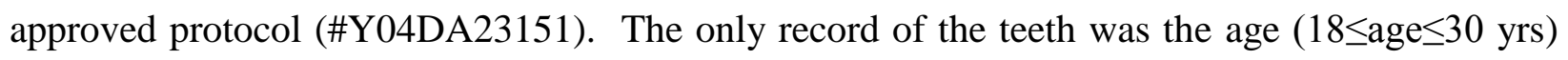
of the donor. The teeth were sectioned using a slicer/grinder (Chevalier Smart-H818II, Chevalier 
Machinery, Santa Fe Springs, CA, USA) with diamond abrasive slicing wheels (\#320 mesh abrasives) and copious water coolant. All sections were obtained from the mid coronal region with necessary geometry for the specimens (Figures 1). The remaining materials included either Single Bond Plus (SB: 3M ESPE) or Scotchbond Multi-Purpose (SBMP, 3M ESPE) adhesive and Z100 (3M ESPE) resin composite.

The flexure strength and stress-life fatigue behavior was evaluated using the Twin Bonded Interface (TBI) approach. The specimens (Figure 1(a)) were prepared using a molding process after Mutluay et al. [27]. Briefly, the adhesive (SB or SBMP) was applied to the two opposing surfaces of rectangular beams (roughly $2 \times 2 \times 10 \mathrm{~mm}^{\wedge} 3$ ) of mid-coronal dentin (Fig. 1(a)) according to the manufacturer's recommendations. Bonding with each of the two adhesive systems was preceded by the recommended $15 \mathrm{sec}$ etch (SB 37\% phosphoric etchant) and rinse. Then the beams were placed within a dedicated mold with the tubules oriented nominally parallel to the bonding interface, akin to the walls of a Class II preparation. Restorative resin composite (Z100, 3M ESPE) was applied incrementally from the dentin beam surface and distributed incrementally to fill the mold cavities on each side of the dentin beam. The composite was cured for $40 \mathrm{sec}$ on both sides using a quartz-tungsten-halogen light-curing unit (Demetron VCL 401, Demetron, CA, USA) with output intensity of $600 \mathrm{~mW} / \mathrm{cm}^{\wedge} 2$ and with tip diameter wider than $10 \mathrm{~mm}$. The bonded sections were released from the mold and sectioned using the slicer/grinder to obtain TBI specimens roughly $2 \mathrm{~mm} \times 2 \mathrm{~mm} \times 12 \mathrm{~mm}$ (Fig. 1(a)). Control specimens consisting of the Z100 resin composite only were prepared using the molding and sectioning process. A total of $105 \mathrm{TBI}$ specimens were prepared, which consisted of 35 for each of the three groups. All of the specimens were inspected, polished lightly with hydration using \#600 
mesh emery paper, and stored in HBSS at room temperature $\left(22^{\circ} \mathrm{C}\right)$ for a minimum of $48 \mathrm{~h}$ prior to further evaluation.

Bonded interface Compact Tension (CT) specimens were prepared using identical bonding procedures and a molding technique similar to that used for the TBI specimens. Briefly, sections of dentin were obtained representing half of the completed CT specimen geometry (Figure 1(b)). Either the SB or SBMP was applied to one edge according to the manufacturer's recommendations; etching preceded application of the adhesives as previously described. Thereafter, the dentin sections were placed in the mold, and the remainder was filled incrementally with the resin composite to complete the CT geometry. A thin Mylar sheet was placed at one end of the interface to introduce a molded notch (evident in Figure 1(b)). The resin composite was cured for $40 \mathrm{sec}$ on each side. The specimens were lightly sanded and two holes were introduced for loading. In addition, the mylar strip was removed and the notch tip was sharpened using a razor blade and diamond paste. A detailed description of the procedures for preparing the interface CT specimens has been presented previously [26]. CT specimens were also prepared of resin adhesive (SB or SBMP) and Z100 composite (control) without a bonded interface using the molding approach. A total of 25 specimens were prepared overall, which included 5 each for the two bonded interface groups (SB and SBMP) and two adhesive groups (SB and SBMP) and 5 specimens of the Z100). All specimens were stored in HBSS at room temperature $\left(22^{\circ} \mathrm{C}\right)$ for a minimum of $48 \mathrm{~h}$ prior to further evaluation.

The TBI specimens were evaluated under quasi-static and cyclic four-point flexure using a universal testing system (EnduraTEC Model ELF 3200, Minnetonka, MN, USA) with load capacity and sensitivity of $225 \mathrm{~N}$ and $\pm 0.01 \mathrm{~N}$, respectively. All experiments were performed within a bath of Hanks Balanced Salt Solution (HBSS) at room temperature. The specimens were 
placed in the fixture such that the outer dentin (closest to the occlusal surface) was subjected to tension. Quasi-static loading was applied using displacement control at a rate of $0.06 \mathrm{~mm} / \mathrm{min}$. The strength (S) of the beams was estimated using conventional beam theory [28] in terms of the maximum measured load $(\mathrm{P})$ and beam geometry (width $\mathrm{b}$, thickness $\mathrm{h}$ ) according to $\mathrm{S}=3 \mathrm{Pl} / \mathrm{bh}^{2}$, where 1 is the distance from interior and exterior supports $(1=3 \mathrm{~mm})$. Ten specimens $(\mathrm{N}=10)$ were evaluated in each group. The flexure strengths of the groups were compared using a oneway ANOVA and Tukey's HSD post-hoc analysis with the critical value (alpha) set at 0.05.

Cyclic loading of the TBI specimens was conducted using the same flexure configuration (Fig. 1(a)) under load control with frequency of $4 \mathrm{~Hz}$ and stress ratio $(\mathrm{R}=$ ratio of minimum to maximum cyclic load) of 0.1 . The cyclic loading experiments were initiated with maximum stress of approximately $90 \%$ of the flexural strength identified from the quasi-static results. For successive specimens, the maximum cyclic load was decreased in increments of $5 \mathrm{MPa}$ or less according to the staircase method of evaluation [29]. The process continued until reaching a flexure stress amplitude at which the specimens did not fail within $1.2 \times 10^{\wedge} 6$ cycles. The cyclic stress amplitude was plotted in terms of the number of cycles to failure in log-normal format. The data for those that failed were fit using non-linear regression with a Basquin-type model [30] according to

$$
\sigma=\mathrm{A}(\mathrm{N})^{\mathrm{B}}
$$

where A and B are the fatigue-life coefficient and exponent, respectively. The constants were obtained from a power law regression of the fatigue responses. The apparent endurance limit was estimated from the models for a fatigue limit defined at $1 \times 10^{\wedge} 7$ cycles after [27, 31, 32]. Twenty-five specimens were evaluated for each of the SB and SBMP bonded interfaces and the control (Z100) for an overall total of 75 specimens. The fatigue life responses were compared 
with data for coronal dentin presented most recently [33]. The fatigue life distributions were compared using the Wilcoxon Rank Sum Test with $\mathrm{p} \leq 0.05$ considered significant.

The CT specimens were evaluated using the aforementioned equipment and specialized fixtures with the specimens immersed in HBSS at room temperature $\left(22^{\circ} \mathrm{C}\right)$. Opening mode (Mode I) loading was applied under load control actuation, frequency of $5 \mathrm{~Hz}$ and stress ratio of $\mathrm{R}=0.1$. Measurement of the crack length was accomplished using a microscope system (Optem zoom 70xl 391940, QIOPTIQ, Luxembourg) with CCD camera. The crack lengths were measured under magnification (e.g. 50X) and while being loaded at very low frequency $(0.5 \mathrm{~Hz})$ to maximize their visibility. The increment of crack extension was quantified as a function of the loading increment. In general, the increment of cyclic loading ranged from $5 \leqslant \Delta \mathrm{N} \leqslant 30$ kcycles and the increment of crack growth extended from $0.02 \leqslant \Delta \mathrm{a} \leqslant 0.15 \mathrm{~mm}$. Cyclic loading was continued until the specimen fractured.

Results of the fatigue crack growth experiments were used in constructing plots of the incremental crack growth rate $(\Delta \mathrm{a} / \Delta \mathrm{N})$ in terms of $\Delta \mathrm{K}$ for each specimen. The stress intensity for both the resin composite and the bonded dentin/resin interface specimens was identified as a function of crack length by

$$
\Delta \mathrm{K}=\frac{\Delta \mathrm{P}}{\mathrm{B} \sqrt{\mathrm{W}}}\left(0.1133+0.0841 \alpha+0.3859 \alpha^{2}\right)
$$

where $\Delta \mathrm{P}$ is the maximum opening load, $\mathrm{B}$ is the thickness of the specimen, $\mathrm{W}$ is the distance between the center of the loading points and free boundary in front of the crack, and $\alpha$ is the ratio of the average crack length to specimen width (Fig. 1(b)). Using Eq. (2), the $\Delta \mathrm{K}$ was determined from the applied load range $(\Delta \mathrm{P})$. From these plots, the threshold stress intensity range $\left(\Delta \mathrm{K}_{\mathrm{th}}\right)$ was estimated by inspection, which represents the minimum stress intensity for 
cyclic crack extension. The steady-state portion of the fatigue crack growth responses was identified and modeled using the Paris Law [34] according to

$$
\frac{\mathrm{da}}{\mathrm{dN}}=\mathrm{C}(\Delta \mathrm{K})^{\mathrm{m}}
$$

where $\mathrm{C}$ and $\mathrm{m}$ are the fatigue crack growth coefficient and exponent, respectively. The average values of $\mathrm{C}$ and $\mathrm{m}$ were determined for each group of specimens. A single factor analysis of variance (ANOVA) and Tukey-Kramer tests were performed to identify significant differences between the fatigue crack growth parameters. Previous results for fatigue crack growth in human dentin [35] were compared with those for the resin adhesive, resin composite and resin/dentin interface specimens.

The fractured specimens were evaluated via Scanning Electron Microscopy (SEM) to identify the origins of failure and potential mechanisms of degradation. The evaluation was conducted using a FEI Model Nova NanoSEM 450 (Hillsboro, OR, USA) in either secondary electron imaging (SEI) or back scattered electron (BEC) imaging modes. Prior to this analysis the specimens were dehydrated in an ascending ethanol series (70-100\%), fixed in hexamethyldisilazane, polished lightly in series using \#800, \#2400 and \#4000 emery cloth and then sputtered with gold/palladium to enhance conductance of the hard tissue and resin adhesive.

\section{RESULTS}

Results from quasi-static loading of the TBI specimens to failure are shown in Figure 2. As evident from the distributions and statistical comparison, there was no significant difference ( $>0.05$ ) between the flexure strengths of the SB and SBMP groups. However, the bonded interfaces exhibited significantly lower strength than that of the Z100 control and coronal dentin alone. 
Fatigue life diagrams for the bonded interfaces prepared with SB and SBMP adhesives are shown in Figures 3(a) and 3(b), respectively. Basquin-type power law models are listed with the results of each material, which describe the mean fatigue strength distribution. As evident from a comparison of the data in these two figures, the bonded interfaces prepared with SB adhesive exhibited much greater variation in fatigue strength than those prepared with SBMP. According to the Wilcoxon Rank Sum test, the fatigue strength of the interface prepared with SB adhesive was significantly lower $(Z=-3.45 ; \mathrm{p} \leq 0.001)$ than that for SBMP. The fatigue life diagrams for the two bonded interfaces are compared with that of the control (Z100) in Figure 3(c), along with data for coronal dentin [33]. Note that the diagrams are presented for lives $\mathrm{N} \geq$ 100 cyles. A presentation of fatigue responses in this manner shows that the fatigue strength of the bonded interfaces is significantly lower than that of the resin composite and dentin. The stress-life fatigue constants for each of the materials are listed in Table 1 and were used to estimate an apparent endurance limit for each of the material systems at $1 \times 10^{7}$ cycles. From that approach, the apparent endurance limit for the SB and SBMP interfaces were $8.4 \mathrm{MPa}$ and 14.4 $\mathrm{MPa}$, respectively. These values are between only one-quarter and one-third those values for the Z100 control (42 MPa) and dentin (43 MPa).

The fatigue crack growth responses for bonded interface CT specimens prepared with SB adhesive are shown in Figure 4(a). Cumulative results for the SB adhesive (evaluated separately) are shown in this figure as well. Note that only one or two data points were generally obtained for each of the SB adhesive specimens, which is a consequence of rapid crack growth and relative instability in comparison to the interface. The Paris Law exponent and coefficient are shown with the response, along with the stress intensity threshold. The $\Delta \mathrm{K}_{\mathrm{th}}$ for the adhesive and bonded interface are 0.13 and $0.60 \mathrm{MPa} \bullet \mathrm{m}^{0.5}$, respectively, and listed in Table 2. Cumulative 
fatigue crack growth responses for the SBMP bonded interface and the adhesive are shown in Figure 4(b). Consistent with results obtained for SB, the SBMP resin adhesive exhibited significantly lower resistance to fatigue crack growth than the bonded interface. The $\Delta \mathrm{K}_{\mathrm{th}}$ for the adhesive and the bonded interface are 0.3 and $0.5 \mathrm{MPa} \cdot \mathrm{m}^{0.5}$, respectively.

The fatigue crack growth responses for the bonded interface are presented in Figure 5, along with results for the Z100 (control) and the responses reported for young coronal dentin (perpendicular to the tubules) [35]. There is no significant difference $(p>0.05)$ in the fatigue crack growth responses between the $\mathrm{Z} 100$ and dentin. The $\Delta \mathrm{K}_{\mathrm{th}}$ for the $\mathrm{Z} 100$ and dentin are 0.7 $\mathrm{MPa}$ and $0.8 \mathrm{MPa} \cdot \mathrm{m}^{0.5}$, respectively, which are both at least $20 \%$ greater than those obtained for the bonded interfaces; the differences are significant $(\mathrm{p} \leq 0.05)$. As evident in Figure 5 , the fatigue crack growth resistance of the bonded interfaces prepared with SB adhesive was significantly greater than that resulted from SBMP. A summary of the average values for Paris Law parameters for all the materials evaluated is listed in Table 2.

The fracture surfaces of the TBI specimens and the remaining interface that did not fail by fatigue were evaluated using the SEM (Figure 6). For both resin adhesive systems, failure occurred on the tensile side of the specimen. In the SB specimens, failure initiated within the resin composite or at the interface of the resin adhesive and composite. An examination of the tensile surface of the interfaces that did not fracture (but were subjected to high cycle loading) revealed evidence of crack initiation and fatigue failure along the boundary of larger reinforcement particles within the polymer matrix (Figure 6(a)). For the SBMP specimens, failure was found to initiate predominately within the resin adhesive or within the hybrid layer as evident in Figure 6(b). The progression of failure then continued within the hybrid layer or through a combination of the hybrid layer and adhesive. While failure typically initiated within 
the resin adhesive in the SB specimens, the crack would then transition to the resin composite. An example for a representative SBMP interface is shown in Figure 6(c).

Fracture surfaces of the interface CT specimens were also evaluated after the fatigue crack growth testing. Micrographs from the fracture surfaces of specimens prepared with SB adhesive are shown in Figure 7(a) and 7(b), at two different levels of magnification. Similar micrographs from a CT specimen prepared with SBMP are shown in Figure 7(c) and 7(d), respectively. All of the micrographs represent the dentin side of the fracture surface. For both adhesive systems, cyclic crack growth occurred primarily within the hybrid layer and at the interface of the resin penetration within dentin. The lower magnification micrographs for the two resin systems (i.e. Figures 7(a) and 7(c)) show similar characteristics, including evidence of resin infiltration within the dentin tubules and failure of the resin tags either above or below the fracture surface proper. There is also some evidence of tubules without resin, which was most common in the interfaces of the SBMP specimens (Fig. 7(c)) and is indicative of tag pullout. A clearer view of the differences between the SB and SBMP systems is evident from the micrographs at higher magnification in Figures 7(b) and 7(d), respectively. Clearly more tubule lumens of the SB bonded sample (Figure 7(b)) remain filled with resin. In addition, the tags appear more coherent with the surrounding matrix, with a great number of tag fractures at the crack plane. There is more evidence of debonding between the tags and matrix in the SBMP interface (Figure 7(c)), implying that the tags operated independently of the matrix.

\section{DISCUSSION}

In comparison to the number of reported studies on the fatigue properties of resin composites, few exist in this area for resin-dentin bonds. Far fewer have developed fatigue life 
diagrams that encompass the entire stress-life response. Prior evaluations have largely estimated the interface fatigue strength at a specific finite life (e.g. 100k cycles) using the staircase approach [e.g. 19, 21, 36]. Staninec et al. [22,23] performed fatigue tests on dentin-resin bonded interface specimens in flexure and constructed fatigue life diagrams that spanned lives from 1 to 1 million cycles. That approach requires more substantially more time, but there are definite benefits. It is also essential for developing a comprehensive understanding of the fatigue behavior.

The apparent endurance limits for the SBMP resin-dentin interface and Z100 composite were roughly $14 \mathrm{MPa}$ and $42 \mathrm{MPa}$, respectively. These values are quite similar to the responses reported by Mutluay et al. [27] for resin-dentin bonds with Clearfil SE Bond (13 MPa) and AP-X composite (48 MPa) using the TBI approach. Based solely on a comparison of the endurance limits the fatigue resistance of resin-dentin interfaces bonded with SBMP and SE would appear equivalent. But a comparison of the fatigue life distributions suggests otherwise. For the resindentin bonds made with Clearfil SE Bond, the fatigue life distribution exhibited a Basquin exponent of (-0.09) [27], which is far greater in magnitude than those for either SB or SBMP (Table 1). The lower slopes for the SB and SBMP interfaces (as identified by B) indicate that they are less reliable under cyclic loading than the interface prepared with Clearfil SE Bond. There is no distinct trend in the fatigue life distributions of the SB and SBMP bonded interfaces with stress (Figure 3). Defects facilitate spurious failures of these bonded interfaces when subjected to cyclic loading. As such, the number of cycles to failure is largely a function of the defect population and size, rather than simply stress. Results reported for Clearfil SE Bond show that this type of failure is less common. Hence, without development of the fatigue life 
diagrams, false interpretations of the interface fatigue behavior are possible, even when using the exact same experimental method for assessment.

As suggested by Belli et al. [24], the use of complementary measures for evaluating the bonded interface durability has distinct advantages. First, a comparison of the apparent strength under quasi-static (Figure 2) and cyclic loading (Figure 3(c)) showed that although there was no significant difference in strength of the SB and SBMP bonded interfaces under quasi-static loading, there was a significant difference in the fatigue strength. Silva et al. [37] reported on the microtensile bond strength of SB and SBMP with Z350 after 7-day exposure in artificial saliva and found that the SBMP was significantly stronger. The difference was only $10 \%$, which is of questionable clinical importance. In contrast, the apparent endurance limit of the SBMP bonded interface was over $70 \%$ greater than that achieved by SB in the current study. That implies that the results of static evaluations are not a reliable forecast of the fatigue performance, and that a complementary assessment of static and fatigue strength is very useful.

Results from the fatigue crack growth analysis appear to contradict those of the stress-life fatigue responses. For example, the interfaces prepared with SB exhibited significantly greater $\Delta \mathrm{K}_{\mathrm{th}}$ (Table 1) and lower growth rates across the applied stress intensity range (Figure 5) than obtained for the SBMP. In fact, the average incremental crack growth rate for the SBMP interface is approximately 10 times greater than that for SB at equivalent values of driving force (i.e. $\Delta K)$. According to the fracture surfaces from fatigue crack growth in Figure 7 both interfaces failed within the hybrid layer. However, the features evident in the micrographs for the SBMP (Fig. 7(d)) suggest that the adhesive has a poorer degree of integration within the dentin matrix. Both adhesives exhibit good penetration into dentinal tubules from the distribution of resin tags, but tag fractures in the SBMP are often displaced from the fracture surface proper; 
many tags appear dislodged from their foundation by cyclic loading, which was also noted in the TBI specimens (Figure 6(b)). Those features are not evident for the SB (Fig. 6(b) and 7(b)). Therefore, while the SB exhibits inferior resistance to fatigue, it has greater damage tolerance as evident from the superior resistance to fatigue crack growth. Those findings could not be obtained from an evaluation of the interface using microtensile tests.

Resin tag retention in dentinal tubules depends on the liquid comonomers wetting the circumferential collagen fibrils lining the tubule wall. Apparently the resin tags of SBMP (Fig. 7(d)) did not permeate between the collagen fibrils of the tubule walls to anchor the tags in the intertubular dentin. When the bonded assembly was stressed, many tags pulled out of the tubules, while others had enough shear strength at the tubule walls to resist pull out, fracturing the tags in the same plane as the growing crack. Presumably, resin tags created by SB wet the collagen fibrils lining the tubules, producing improved anchoring of resin tags in the tubules and improved stress transfer to resin bond dentin. Nearly all SB resin tags remained in the tubules after the tags fractured at the same plane as the developing crack.

The composition of SB and SBMP adhesives differs significantly. Although the comonomer compositions of both adhesives are similar, SB adhesive is solvated by ethanol and water, while SBMP is solvent-free [38]. And while SBMP primer contains HEMA and water that should have wet the surface of the dentin and penetrated into the tubule orifices, there may have been inadequate mixing of primer components with the SBMP adhesive. Careful examination of the circumferential intratubular collagen fibrils reveals individual collagen fibrils suggesting that SBMP adhesive was unable to wet them.

There was a significant difference between the fatigue crack growth resistance of the SB and SBMP interfaces, but the differences between the interfaces and the corresponding adhesives 
were even greater (Figure 4). Without collagen reinforcement the adhesives exhibited a $\Delta \mathrm{K}_{\mathrm{th}}$ significantly lower than the bonded interfaces (Table 2). The SB adhesive was the least resistant overall (Figure 4(a)) despite the larger resistance of the SB interface to fatigue crack growth. Fatigue crack growth within the bonded interface specimens occurred within the hybrid layer, a composite of adhesive and fibril reinforcement. Hence, the disparity between the bonded interface and adhesive specimen performance underscores the importance of dentin collagen to bond durability. A comparison of Figures 4(a) and 4(b) indicates that collagen reinforcement is most important to the fatigue crack growth resistance of the SB. As such, the inferior stress-life fatigue strength of the SB interfaces could be attributed to a smaller degree of resin penetration for that tubule orientation (tubules parallel to the bonding surface) and the low fatigue crack growth resistance of the adhesive. Though speculative, that would place greater dependence on the resin properties in fatigue. The results could also be interpreted to suggest that that resin integration into collagen fibrils in the hybrid layer by SB adhesive is more effective than with SBMP. Independent of all other concerns, resin-dentin bonds placed in areas of lower relative collagen content (i.e. deep dentin [39]) will be more susceptible to failure by fatigue crack growth.

The term "durability" in this manuscript has been used to refer to the material's capacity to endure cyclic loading. But there are far more threats to the integrity of resin-dentin adhesive bonds than simply mechanical fatigue. The experimental evaluation was conducted on interfaces that were not subject to recognized challenges of the oral environment. Nor were the samples aged for a prolonged period prior to testing. Biofilm attack $[40,41]$ and collagen degradation by endogenous Matrix Metalloproteinases (MMP) [42,43] within the hybrid layer are amongst the most critical. Biofilm attack significantly reduces the fatigue strength of dentin [44] and the 
resistance of the bonded interface to cyclic loading [31]. While MMP activity does not cause an immediate reduction in strength of dentin bonds [45], it is not apparent at what point the degradation becomes significant. Preliminary results suggest that the reduction in fatigue crack growth resistance may occur within as little as 3 months [46]. Furthermore, there is some evidence that cyclic stresses contribute to MMP activity [47] and mineralization changes [48, 49]. Additional studies addressing the potential for synergistic degradation between mechanical fatigue and other challenges to the interface appears warranted.

Results of this investigation show that the interfacial structures such as resin tags and collagen fibrils in the hybrid layer and tubule walls may play a critical role on the fatigue crack growth resistance of the bonded interface. They also provide convincing evidence that the integrity of collagen fibrils is essential to bond durability as well. While these findings contribute to our understanding of resin-dentin bond durability, there are some limitations to the investigation that should be considered. Perhaps the most important is that only two commercial adhesives systems were evaluated. Admittedly, the weak links identified for the interfaces developed using SB and SBMP may not be equivalent to those most prominent/detrimental for other adhesives. Herein lies the difficulty of developing a comprehensive understanding of bond durability. Additional studies including other bonding systems are necessary to broaden our understanding. One may be concerned that the stress-life and fatigue crack growth portions of the study involved a bonded interface with different tubule orientations. While true, tubule orientation is reportedly of limited or no importance to the microtensile strength of resin-dentin adhesive bonds [50-52]. Tubule orientation is important to the fatigue strength [53] and fatigue crack growth resistance of dentin [35,54], which is attributed to the collagen matrix. The difference in tubule orientation is not expected to have influenced the rank of the fatigue strength 
or fatigue crack growth responses. Nevertheless, no study has explored the importance of tubule orientation to the durability of resin-dentin bonds. This is an important topic and is reserved for future study. In addition, the cyclic loading frequency was nearly twice that expected from mastication (approx. $2 \mathrm{~Hz}$ ) [55]. Relevant to this concern, the experimental activities of this study extended over well more than a year, and the higher frequency was chosen to reduce the time required for completion. A stress-life fatigue evaluation requires time and is perhaps the most costly part of durability studies. Concessions can be made in the number of samples or the number of cycles over which the study is conducted, but those shortcuts are more likely to degrade the quality of findings.

\section{CONCLUSIONS}

On the basis of the experimental results and analysis, the following conclusions are drawn:

1. There was no significant difference between the flexure strength of the bonded interfaces prepared with SB and SBMP adhesives. The average flexure strength for the two systems was $27 \pm 10$ and $39 \pm 18 \mathrm{MPa}$, respectively.

2. The resin-dentin bonds prepared with SBMP exhibited significantly greater fatigue strength than with the SB adhesive. The apparent endurance limit for the SB and SBMP interfaces were 8.4 and 14.4 MPa, respectively. These values were approximately one-third of that for the Z100 composite (43 MPa).

3. The interfaces prepared with SBMP exhibited significantly lower resistance to cyclic crack growth than those prepared with the SB. The stress intensity threshold for the SBMP and SB interfaces was roughly 0.5 and $0.6 \mathrm{MPa} \bullet \mathrm{m}^{0.5}$, respectively. However, the lowest stress intensity threshold overall was exhibited by the SB adhesive. 
4. Resin tags that are not well hybridized into the surrounding intertubular dentin and hybrid layers that are not effectively reinforced (due to thick adhesive layer or a limited degree of intact collagen) were identified as detrimental weak links. These qualities limit the durability of adhesive bonds to dentin.

\section{ACKNOWLEDGEMENTS}

The authors acknowledge support from the National Institutes of Health (NIDCR R01 DE015306-06 Pashley) and the National Science Foundation (NSF DMR 1337727 Takacs). The authors also gratefully acknowledge 3M ESPE for their generous donation of bonding supplies and resin composite.

\section{REFERENCES}

1. Lohbauer U, Belli R, Ferracane JL. Factors involved in mechanical fatigue degradation of dental resin composites. J Dent Res, 2013; 92:584-91.

2. Zhang Y, Sailer I, Lawn BR. Fatigue of dental ceramics. J Dent, 2013; 41:1135-47.

3. Braem M, Lambrechts P, Vanherle G. Clinical relevance of laboratory fatigue studies. J Dent, 1994; 22:97-102.

4. Baran G, Boberick K, McCool J. Fatigue of restorative materials. Crit Rev Oral Biol Med, 2001; 12:350-360.

5. Takeshige F, Kawakami Y, Hayashi M, Ebisu S. Fatigue behavior of resin composites in aqueous environments. Dent Mater, 2007; 23:893-99.

6. Drummond JL. Degradation, fatigue, and failure of resin dental composite materials. J Dent Res, 2008; 87:710-9. 
7. Drummond JL, Lin L, Al-Turki LA, Hurley RK. Fatigue behavior of dental composite materials. J Dent, 2009; 37: 321-330.

8. Shah MB, Ferracane JL, Kruzic JJ. Mechanistic aspects of fatigue crack growth behavior in resin based dental restorative composites. Dent Mater, 2009; 25:909-16.

9. Shah MB, Ferracane JL, Kruzic JJ. R-curve behavior and micromechanisms of fracture in resin based dental restorative composites. J Mech Behav Biomed Mater, 2009; 2:502-11.

10. Ornaghi BP, Meier MM, Lohbauer U, Braga RR. Fracture toughness and cyclic fatigue resistance of resin composites with different filler size distributions. Dent Mater, 2014; 30:74251.

11. Belli R, Geinzer E, Muschweck A, Petschelt A, Lohbauer U. Mechanical fatigue degradation of ceramics versus resin composites for dental restorations. Dent Mater, 2014; 30:424-32.

12. Della Bona A, Watts DC. Evidence-based dentistry and the need for clinically relevant models to predict material performance. Dent Mater 2013; 29:1-2.

13. Ferracane JL. Resin-based composite performance: are there some things we can't predict? Dent Mater, 2013; 29:51-8.

14. Spencer P, Ye Q, Park J, Topp EM, Misra A, Marangos O, et al. Adhesive/Dentin interface: the weak link in the composite restoration. Ann Biomed Eng, 2010; 38:1989-2003.

15. Pashley DH, Tay FR, Breschi L, Tjäderhane L, Carvalho RM, Carrilho M, et al. State of the art etch-and-rinse adhesives. Dent Mater, 2011; 27:1-16.

16. Ruse ND, Shew R, Feduik D. In vitro fatigue testing of a dental bonding system on enamel. J Biomed Mater Res, 1995; 29:411-5.

17. Drummond JL, Sakaguchi RL, Racean DC, Wozny J, Steinberg AD. Testing mode and surface treatment effects on dentin bonding. J Biomed Mater Res, 1996; 32:533-41.

18. Frankenberger R, Krämer N, Petschelt A. Fatigue behaviour of different dentin adhesives. Clin Oral Investig, 1999; 3:11-7.

19. Frankenberger R, Strobel WO, Krämer N, Lohbauer U, Winterscheidt J, Winterscheidt B, et al. Evaluation of the fatigue behavior of the resin-dentin bond with the use of different methods. J Biomed Mater Res B: Appl Biomater, 2003; 67:712-21.

20. Frankenberger R, Pashley DH, Reich SM, Lohbauer U, Petschelt A, Tay FR. Characterisation of resin-dentine interfaces by compressive cyclic loading. Biomaterials, 2005; 26:2043-52. 
21. De Munck J, Braem M, Wevers M, Yoshida Y, Inoue S, Suzuki K, et al. Micro-rotary fatigue of tooth-biomaterial interfaces. Biomaterials, 2005; 26:1145-53.

22. Staninec M, Kim P, Marshall GW, Ritchie RO, Marshall SJ. Fatigue of dentin-composite interfaces with four-point bend. Dent Mater, 2008; 24:799-803.

23. Staninec M, Nguyen H, Kim P, Marshall GW, Rithchie RO, Marshall SJ. Four-point bending evaluation of dentin-composite interfaces with various stresses. Med Oral Patol Oral Cir Bucal, 2008; 13:E81-4.

24. Belli R, Baratieri LN, Braem M, Petschelt A, Lohbauer U. Tensile and bending fatigue of the adhesive interface to dentin. Dent Mater, 2010; 26:1157-65.

25. Singh V, Misra A, Marangos O, Park J, Ye Q, Kieweg SL, et al. Fatigue life prediction of dentin-adhesive interface using micromechanical stress analysis. Dent Mater, 2011; 27:e187-95.

26. Soappman MJ, Nazari A, Porter JA, Arola D. A comparison of fatigue crack growth in resin composite, dentin and the interface. Dent Mater, 2007; 23:608-14.

27. Mutluay MM, Yahyazadehfar M, Ryou H, Majd H, Do D, Arola D. Fatigue of the resindentin interface: a new approach for evaluating the durability of dentin bonds. Dent Mater, 2013; 29:437-49.

28. Popov EP. Mechanics of Materials. $2^{\text {nd }}$ Edition Prentice Hall Inc.; New Jersey: 1978.

29. Collins JA. "Fatigue testing procedures and statistical interpretations of data" in Fatigue of Metals in Mechanical Design, John Wiley and Sons; 1981.

30. Stephens RI, Fatemi A, Stephens RR, Fuchs HO. Metal fatigue in engineering. 2nd Edition New York: John Wiley and Sons, Inc; 2001.

31. Mutluay MM, Zhang K, Ryou H, Yahyazadehfar M, Majd H, Xu HH, et al. On the fatigue behavior of resin-dentin bonds after degradation by biofilm. J Mech Behav Biomed Mater, 2013; 18:219-31.

32. Yahyazadehfar M, Mutluay MM, Majd H, Ryou H, Arola D. Fatigue of the resin-enamel bonded interface and the mechanisms of failure. J Mech Behav Biomed Mater, 2013; 21:121-32.

33. Lee HH, Majd H, Orrego S, Majd B, Romberg E, Mutluay MM, et al. Degradation in the fatigue strength of dentin by cutting, etching and adhesive bonding. Dent Mater, 2014; 30:106172 .

34. Paris PC, Erdogan F. A critical analysis of crack propagation laws. J Basic Eng, 1963; D85:528-34. 
35. Ivancik J, Majd H, Bajaj D, Romberg E, Arola D. Contributions of aging to the fatigue crack growth resistance of human dentin. Acta Biomater, 2012; 8:2737-46.

36. Erickson RL, De Gee AJ, Feilzer AJ. Effect of pre-etching enamel on fatigue of self-etch adhesive bonds. Dent Mater, 2008; 24:117-23.

37. Silva EM, Almeida GS, Poskus LT, Guimarães JG. Influence of organic acids present in the oral biofilm on the microtensile bond strength of adhesive systems to human dentin. J Biomed Mater Res B Appl Biomater, 2012; 100:735-41.

38. Van Landuyt KL, Snauwaert J, De Munck J, Peumans M, Yoshida Y, Poitevin A, et al. Systematic review of the chemical composition of contemporary dental adhesives. Biomaterials, 2007;28:3757-85.

39. Ryou H, Amin N, Ross A, Eidelman N, Wang DH, Romberg E, et al. Contributions of microstructure and chemical composition to the mechanical properties of dentin. J Mater Sci. Mater Med, 2011; 22:1127-35.

40. Spencer P, Ye Q, Misra A, Goncalves SE, Laurence JS. Proteins, pathogens, and failure at the composite-tooth interface. J Dent Res, 2014;93:1243-9.

41. Delaviz Y, Finer Y, Santerre JP. Biodegradation of resin composites and adhesives by oral bacteria and saliva: a rationale for new material designs that consider the clinical environment and treatment challenges. Dent Mater, 2014; 30:16-32.

42. Liu Y, Tjäderhane L, Breschi L, Mazzoni A, Li N, Mao J, et al. Limitations in bonding to dentin and experimental strategies to prevent bond degradation. J Dent Res, 2011; 90:953-68.

43. Tjäderhane L, Nascimento FD, Breschi L, Mazzoni A, Tersariol IL, Geraldeli S, et al. Strategies to prevent hydrolytic degradation of the hybrid layer-A review. Dent Mater, 2013; 29:999-1011.

44. Do D, Orrego S, Majd H, Ryou H, Mutluay MM, Xu HH, et al. Accelerated fatigue of dentin with exposure to lactic acid. Biomaterials, 2013; 34:8650-9.

45. Montagner AF, Sarkis-Onofre R, Pereira-Cenci T, Cenci MS. MMP inhibitors on dentin stability: A systematic review and meta-analysis. J Dent Res, 2014; 93:733-743.

46. Beitzel D, Zhang Z, Yahyazadehfar M, Mutluay MM, Tay FR, Pashley DH and Arola D. Fatigue behavior of resin-dentin bonds after degradation by MMPs. J Dent Res, 2014; 93 Abstr No. 23.

47. Toledano M, Aguilera FS, Yamauti M, Ruiz-Requena ME, Osorio R. In vitro load-induced dentin collagen-stabilization against MMPs degradation. J Mech Behav Biomed Mater, 2013; 27:10-8. 
48. Toledano M, Aguilera FS, Sauro S, Cabello I, Osorio E, Osorio R. Load cycling enhances bioactivity at the resin-dentin interface. Dent Mater, 2014; 30:e169-88.

49. Toledano M, Osorio E, Aguilera FS, Sauro S, Cabello I, Osorio R. In vitro mechanical stimulation promoted remineralization at the resin/dentin interface. J Mech Behav Biomed Mater, 2014; 30:61-74.

50. Phrukkanon S, Burrow MF, Tyas MJ. The effect of dentine location and tubule orientation on the bond strengths between resin and dentine. J Dent, 1999; 27:265-74.

51. Adebayo AO, Burrow FM, Tyas JM. Bonding of one-step and two-step self-etching primer adhesives to dentin with different tubule orientations. Acta Odontol Scand, 2008; 66:159-68.

52. Schiltz-Taing M, Wang Y, Suh B, Brown D, Chen L. Effect of tubular orientation on the dentin bond strength of acidic self-etch adhesives. Oper Dent, 2011; 36:86-91.

53. Arola DD, Reprogel RK. Tubule orientation and the fatigue strength of human dentin. Biomaterials, 2006; 27:2131-40.

54. Arola D, Reid J, Cox ME, Bajaj D, Sundaram N, Romberg E. Transition behavior in fatigue of human dentin: structure and anisotropy. Biomaterials, 2007; 28:3867-75.

55. Ostry DJ, Flanagan JR. Human jaw movement in mastication and speech. Arch Oral Biol, $1989 ; 34: 685-93$. 
Table 1 Power law constants for the stress-life fatigue response of each material system. The $\mathrm{R}^{\wedge} 2$ values represent the coefficient of determination for each model.

\begin{tabular}{||c|c|c|c||} 
system & $\begin{array}{c}\mathrm{A} \\
(\mathrm{MPa})\end{array}$ & $\mathrm{B}$ & $\mathrm{R}^{\wedge} 2$ \\
\hline $\mathrm{Z} 100$ & 54 & -0.02 & 0.28 \\
\hline SB & 10.6 & -0.014 & 0.11 \\
\hline SBMP & 14.6 & -0.001 & 0.01 \\
\hline Dentin & 114 & -0.06 & 0.77 \\
\hline
\end{tabular}


Table 2 The threshold stress intensity range $\left(\Delta \mathrm{K}_{\mathrm{th}}\right)$ and Paris Law constants $(\mathrm{m}, \mathrm{C})$ for each of the materials evaluated. The constants $\mathrm{m}$ and $\mathrm{C}$ are the exponent and coefficient of the Paris Law (Eqn. 3) and represent the sensitivity to cyclic crack growth and effective growth rate, respectively. For each of the resin adhesives, (adh) and (int) refer to the adhesive and interface, respectively. Values for $\Delta \mathrm{K}_{\mathrm{th}}$ and $\mathrm{m}$ are listed in terms of the average and standard deviation.

\begin{tabular}{l|c|c|c|c|c|c}
\multicolumn{1}{c|}{ Property } & ${ }^{*}$ SB (adh) & SB (int) & SBMP (adh) & SBMP (int) & Z100 & Dentin \\
\hline$\Delta \mathrm{K}_{\mathrm{th}}\left[\mathrm{MPa} \bullet \mathrm{m}^{0.5}\right]$ & $0.13 \pm 0.02$ & $0.6 \pm 0.05$ & $0.3 \pm 0.03$ & $0.5 \pm 0.05$ & $0.7 \pm 0.02$ & $0.8 \pm 0.1$ \\
\hline $\mathrm{m}$ & ${ }^{*} 25<$ & $17.5 \pm 1.1$ & $16.8 \pm 3.0$ & $16.1 \pm 0.6$ & $5.4 \pm 1.3$ & $14.1 \pm 1.6$ \\
\hline $\mathrm{C}\left[(\mathrm{mm} / \mathrm{cycle})\left(\mathrm{MPa} \bullet \mathrm{m}^{0.5}\right)^{-\mathrm{m}}\right]$ & $1.2 \times 10^{50}$ & $2.2 \times 10^{-2}$ & $1.8 \times 10^{3}$ & $1.6 \times 10^{-1}$ & $3.8 \times 10^{-6}$ & $2.7 \times 10^{-5}$
\end{tabular}

*Due to instability in the fatigue crack growth responses, the values of $\mathrm{m}$ and $\mathrm{C}$ for the SB adhesive were determined from assembling the data of all the specimens. These values should be considered as estimates only. 


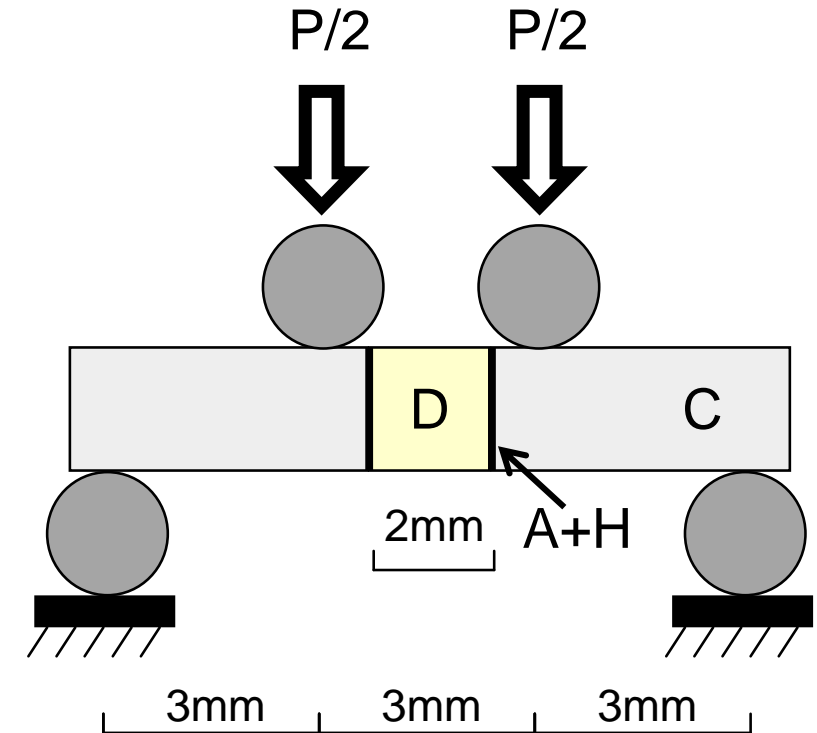

a)

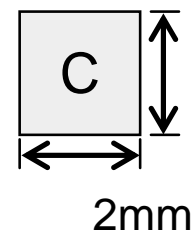

b)

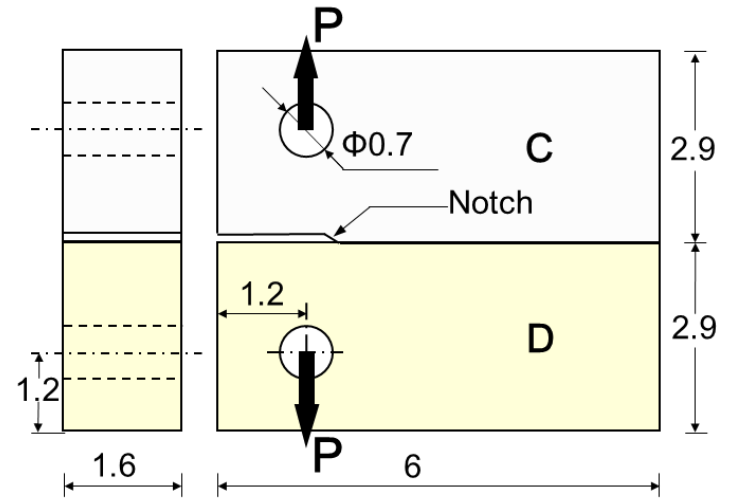

Figure 1 Schematic diagram of the specimen configurations and loading arrangements used for characterizing the fatigue behavior of the bonded interfaces. a) stress-life fatigue, b) fatigue crack growth. The diagrams highlight geometry and materials where $\mathrm{C}=$ resin composite, $\mathrm{D}=$ dentin and $\mathrm{A}+\mathrm{H}$ is the adhesive and hybrid layer. 


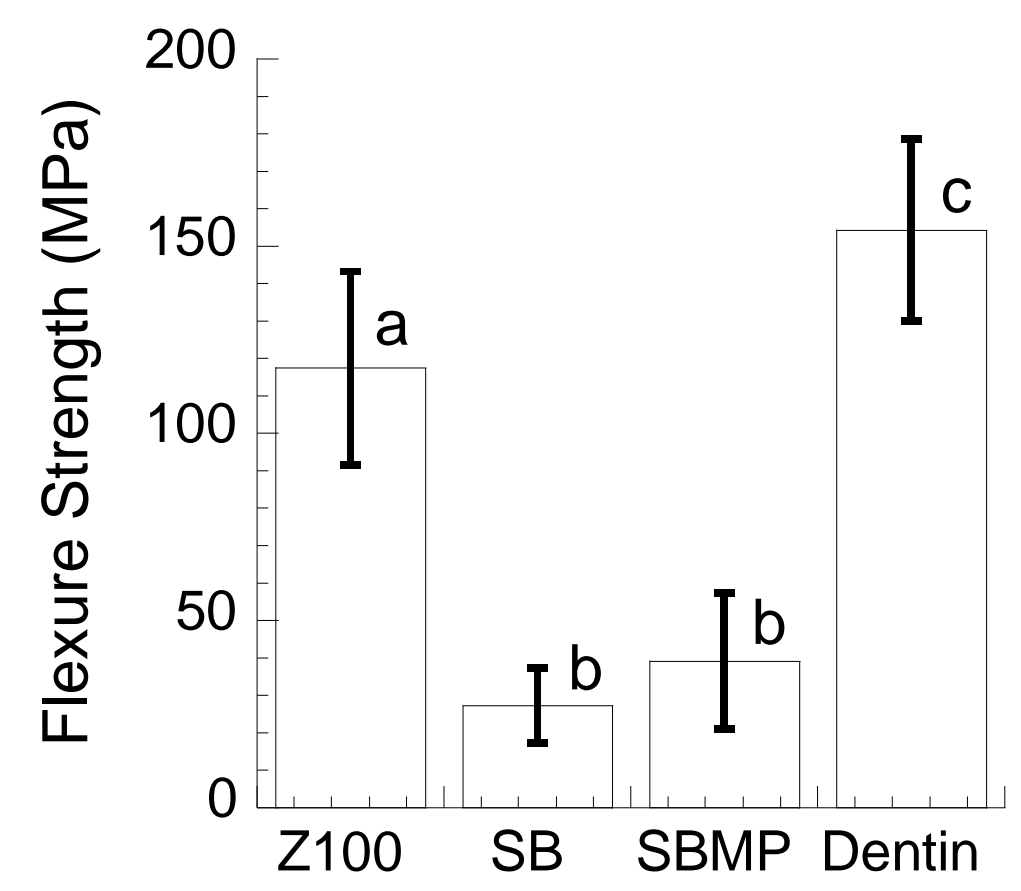

Figure 2 Flexural strength distributions for the bonded interfaces and comparison with results for Z100 and dentin. The error bars represent the standard deviation and columns with different letters are significantly different $(p \leq 0.05)$. 


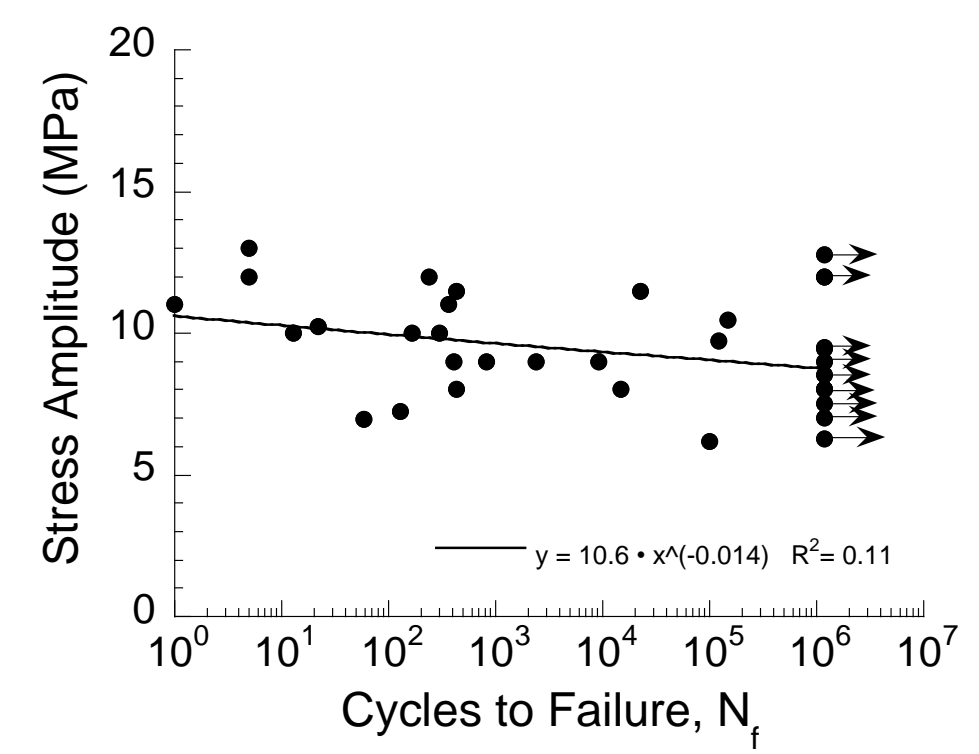

a)

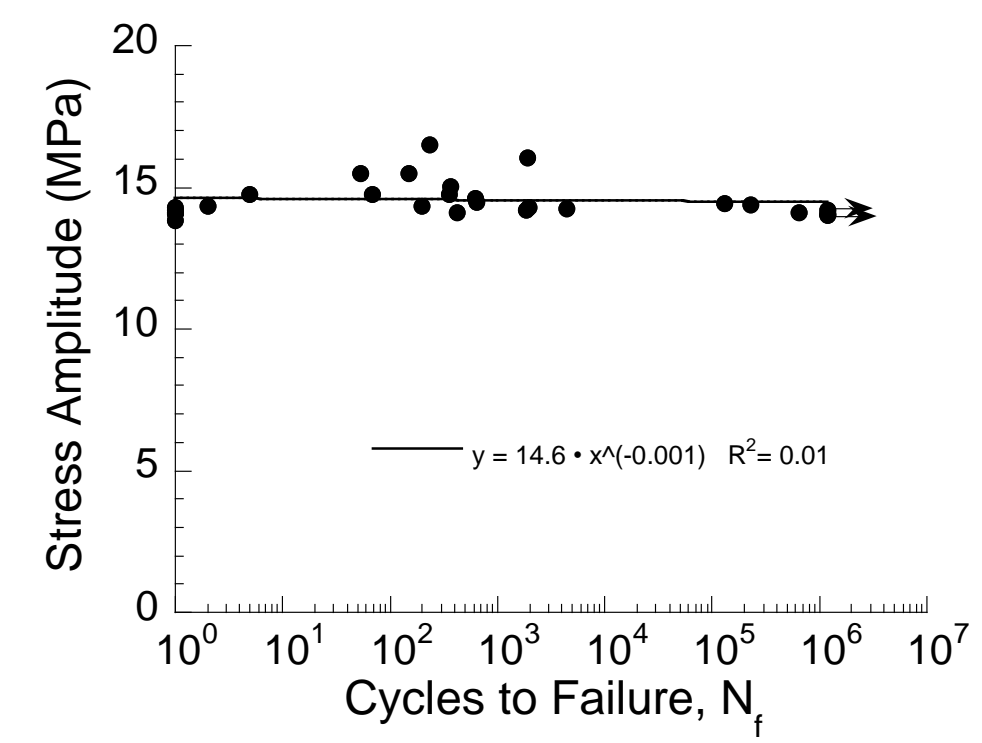

b)

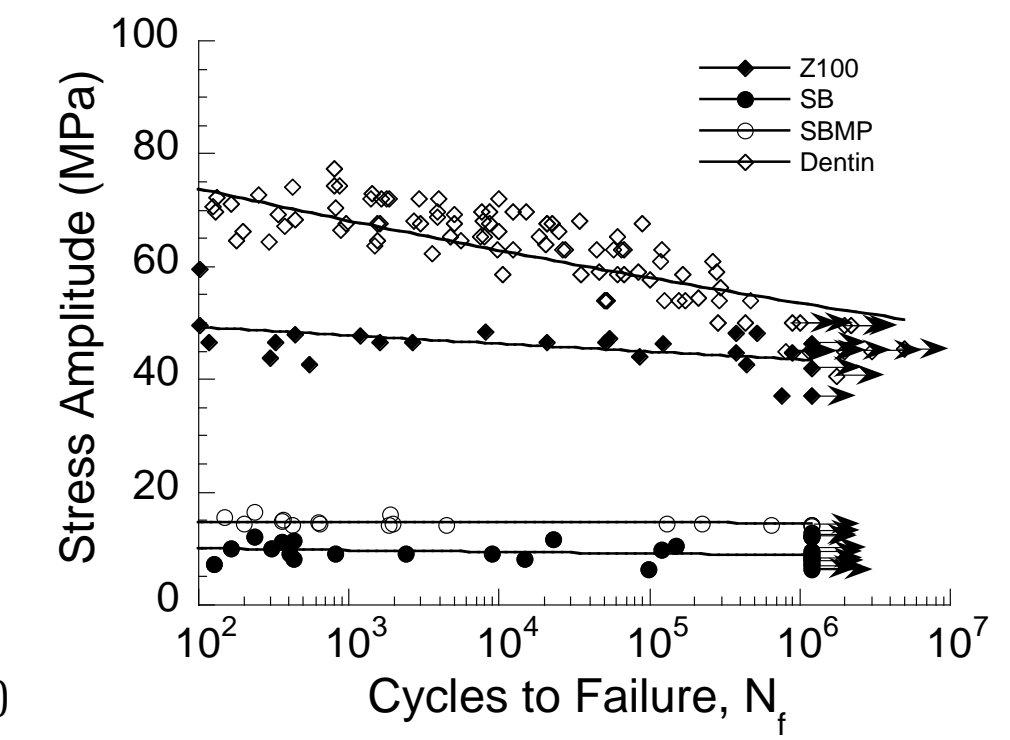

Figure 3 Stress life diagrams for the bonded interface specimens. a) SB, b) SBMP, c) comparison of results from (a) and (b) with Z100 and dentin. Note that the data points with arrows represent those specimens that reached $1.2 \times 10^{6}$ cycles and the test was discontinued. The $\mathrm{R}^{\wedge} 2$ values in (a) and (b) represent the coefficient of determination. Results for dentin in (c) are from [33]. 


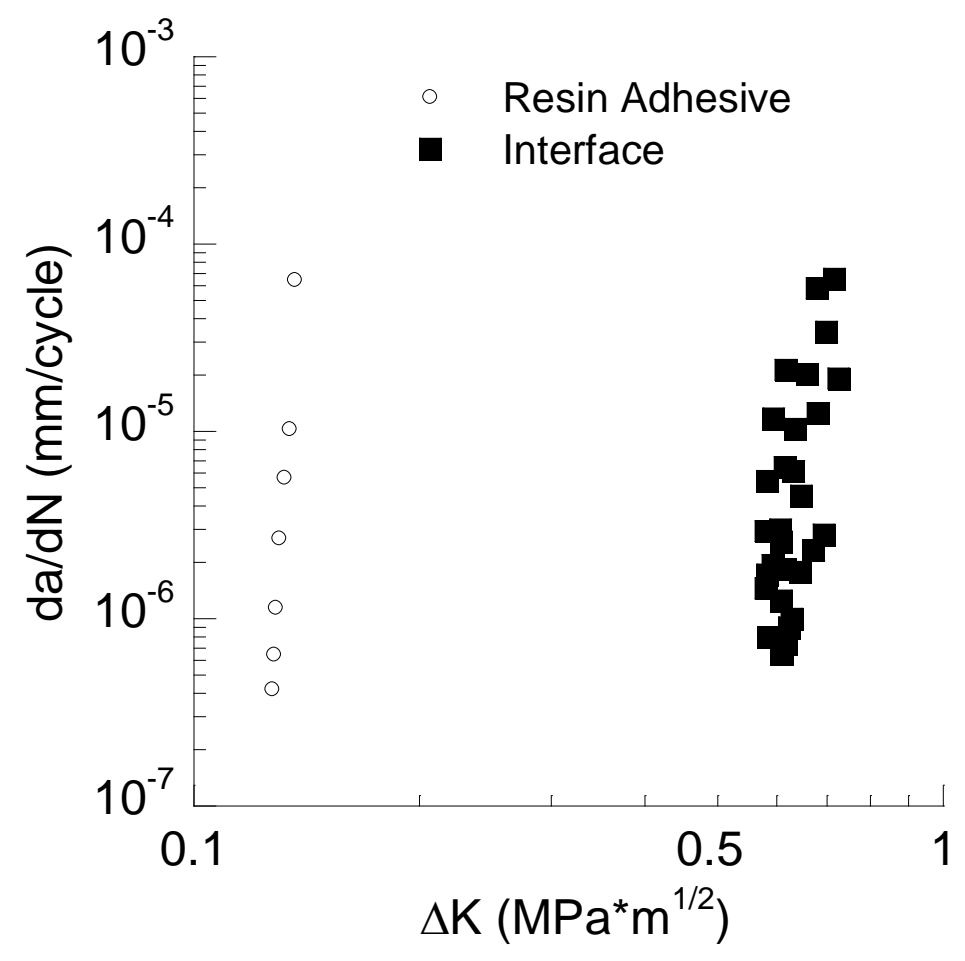

a)

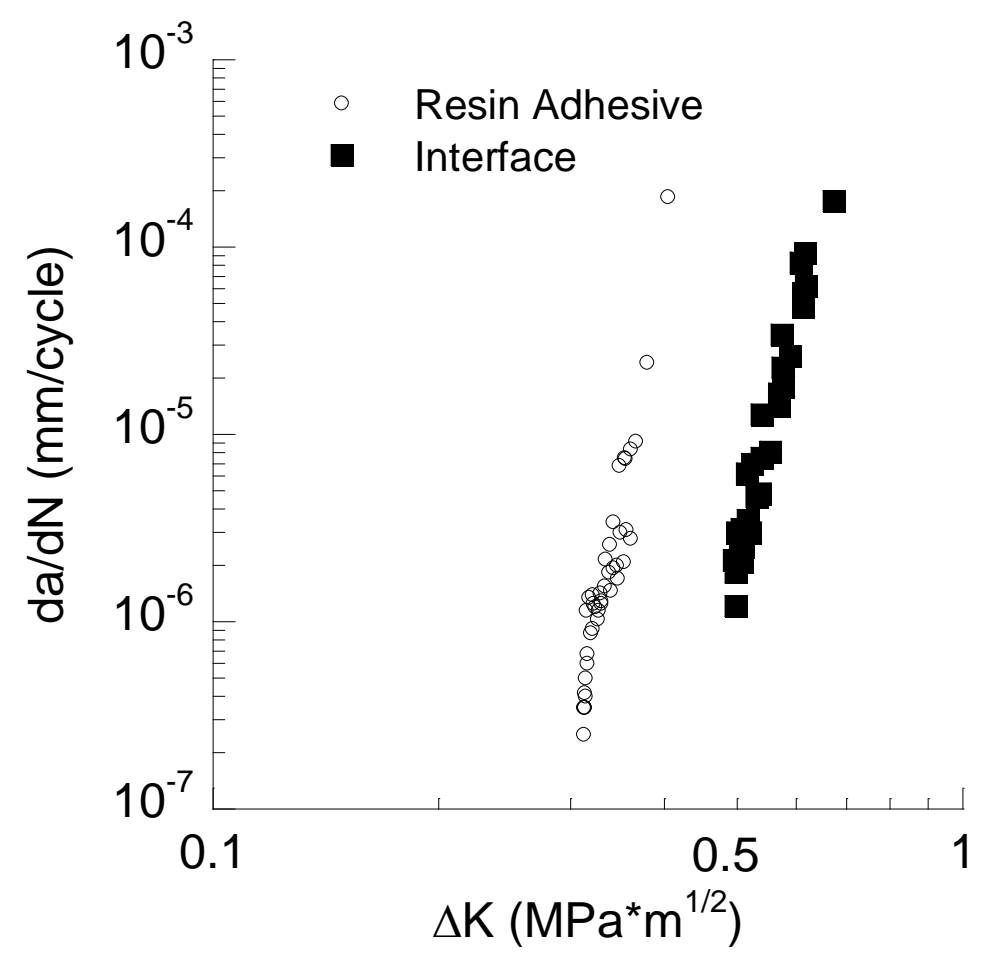

b)

Figure 4 Fatigue crack growth responses. a) cumulative responses for SB adhesive and bonded interface, b) cumulative responses for SBMP adhesive and bonded interface. Note the large disparity in fatigue crack growth resistance between the SB adhesive and bonded interface relative to that for SBMP. 


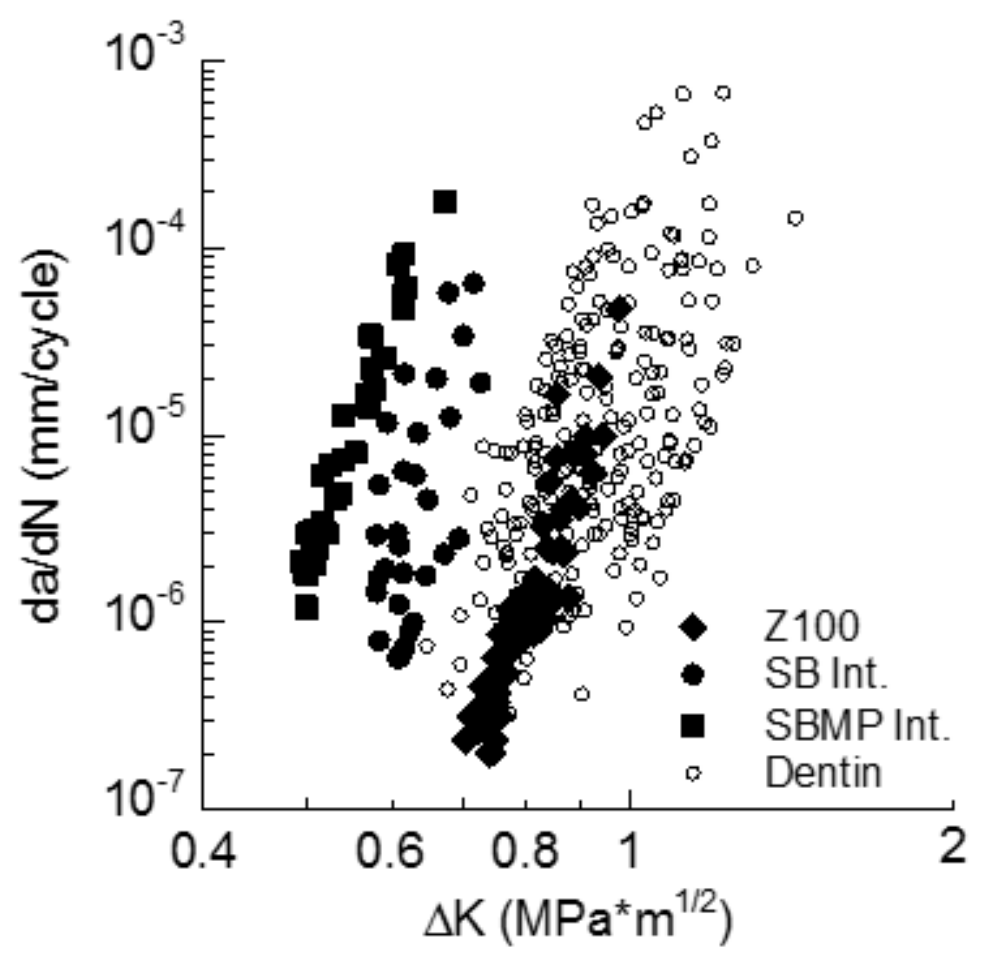

Figure 5 Comparison of the fatigue crack growth resistance of the SB and SBMP interfaces with that for the Z100 and coronal dentin. Results for dentin are for fatigue crack growth perpendicular to the tubules from [35]. 

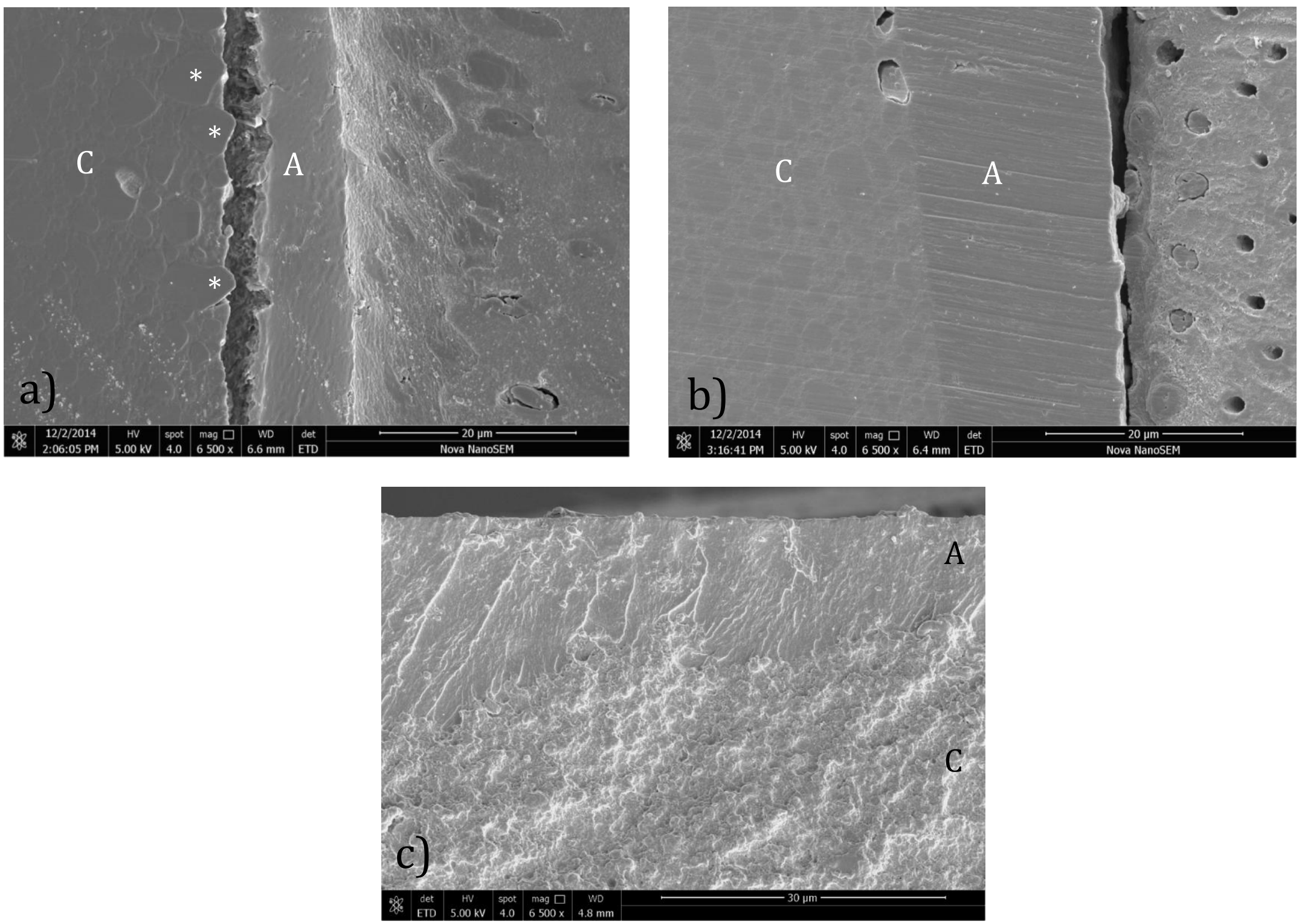

Figure 6 Scanning electron micrographs detailing fatigue failure within selected bonded interface specimens. a) crack initiation on the unbroken side of a SB specimen (tensile side) at the resin composite/adhesive interface. Note the adjacent particulates $(*)$. b) crack initiation on the unbroken side of a SBMP specimen within the hybrid layer. c) view of fracture surface for an SB specimen near the surface of maximum tensile stress. Note the crack begins within the resin and then continues within the resin composite. Resin adhesive (A) and Resin composite (C) are noted in each figure. 

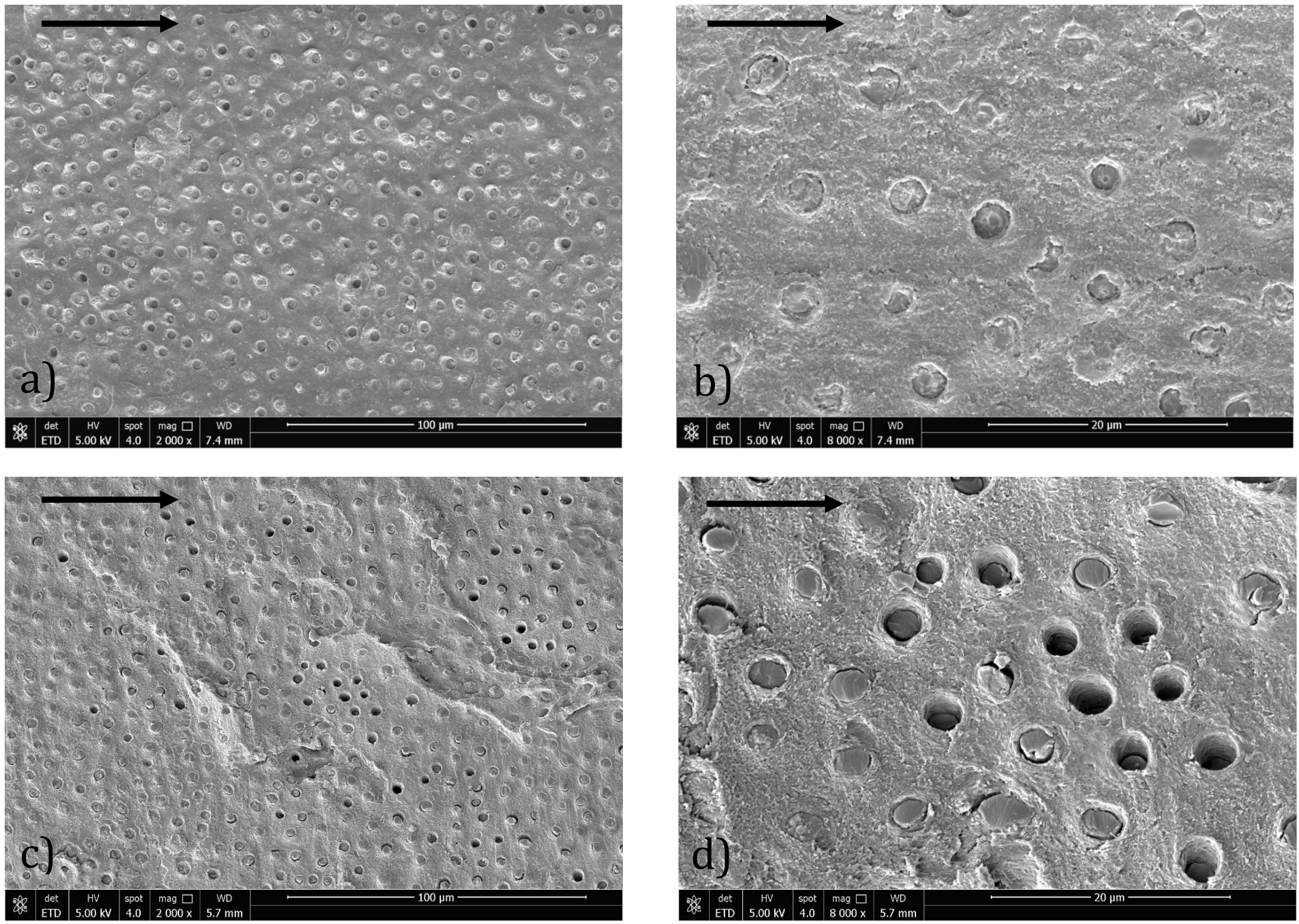

Figure 7 Scanning electron micrographs showing details of the fracture surfaces resulting from fatigue crack growth of the bonded interface specimens. Above shows failure within the hybrid layers of a) SB at 2000X, b) SB at 8000X, c) SBMP at 2000X, d) SBMP at 8000X. The arrows in each figure represent the direction of cyclic crack extension. 